\title{
ELECTROMAGNETIC THEORY
}

Static and Dynamic Electricity

By Prof. William R. Smythe.

(International Series in Physics.) Pp. xviii +560 . (New York and London: McGraw-Hill Book Co., Inc., 1939.) $40 s$.

GOR some time there has been a crying need for a standard text-book on electromagnetic theory, which should give a concise summary of its fundamental principles, and should illustrate them by abundant reference to problems of practical physics and technical engineering. The classical treatises by Jeans and Livens give admirable accounts of the basic laws of electromagnetism, of the mathematical analysis required in problems and of the semi-philosophical problems which lie at the root of the speculative parts of the theory. But it was not their aim to deal in any detail with practical applications or to present the results of the theory in a form adapted for use in research. This magnificent text-book by Prof. W. R. Smythe has as its express object to exhibit the theory of electricity and magnetism in direct relation to problems of research.
The reviewer has used this book in connexion with a variety of practical problems since its publication last November and has never met with disappointment. Every possible aid to the research worker has been given by the author, even to the detail of noting at the foot of each page the system of units employed thereon. The results are always given in the most practical form. Thus, for example, the magnetic field due to a circular loop is not expressed as a useless, slowly convergent series of zonal harmonics but as elliptic integrals which can be rapidly evaluated from tables.

There is a twenty-page index and a careful appendix comparing in detail the standard systems of units. Vector notation is employed throughout. There is a good introduction to the special theory of relativity and also to wave mechanics. The requisite mathematical analysis is dẹveloped as required, but space is saved by referring the student to standard tables of integrals for the more elementary results. This treatise should take its place with those of Jeans and Livens as an indispensable help to every research worker in electromagnetic theory.

G. Temple.

\section{INDIAN PHILOSOPHY}

A History of Indian Philosophy

By Dr. Surendranath Dasgupta. Vol. 3. Pp. xiii +614. (Cambridge: At the University Press, 1940.) 35s. net.

LL those who are interested in Indian
philosophy, and especially the readers of the
first two volumes of this excellent standard and
scholarly work, will welcome the publication of
the third volume as well as the news that the
manuscript of the fourth volume is ready. Prof.
Dasgupta's remarkable exposition of Indian
thought brings home to philosophers that the
history of their subject is incompletely assessed
and understood without a general knowledge at
least of Eastern thought. The difficulty of perusing
manuscripts in Sanskrit and other old tongues of
the Dekkan Peninsula is minimized by the pains-
taking and judicious study carried out by Prof.
Dasgupta, and the results of which are given in his
great work.

The present volume deals more specifically with the religious philosophy of southern Indian schools, which are not orthodox for the most part with regard to official Brahmin thought. The Pañcavātras, for example, are considered of a lower caste and value by the orthodox Brahmins. This volume deals in turn with the Bhaskara school, the Pañcavatras and the Arvars, the Visistadvaita, Yamunacarya, the important Ramanuja school and the Nimbarka doctrines, and the Vijnana Bhiksu. The book ends with a detailed exposition of selected Puranas and the usual bibliographies and indexes.

The analysis of these teachings shows the alertness and depth of Indian thought at its best, whatever be their orthodoxy. Problems of knowledge, of religious psychology, of moral experience are well illustrated. The discussion of the nature of time according to Venkatanatha, to take one instance, is very illuminating, and exhibits the closeness of the Indian views with some Western doctrines. In fact, the comparative value of Indian philosophy is one of the characteristics that should induce European scholars to give more time and thought to it.
T. GReEnwood. 